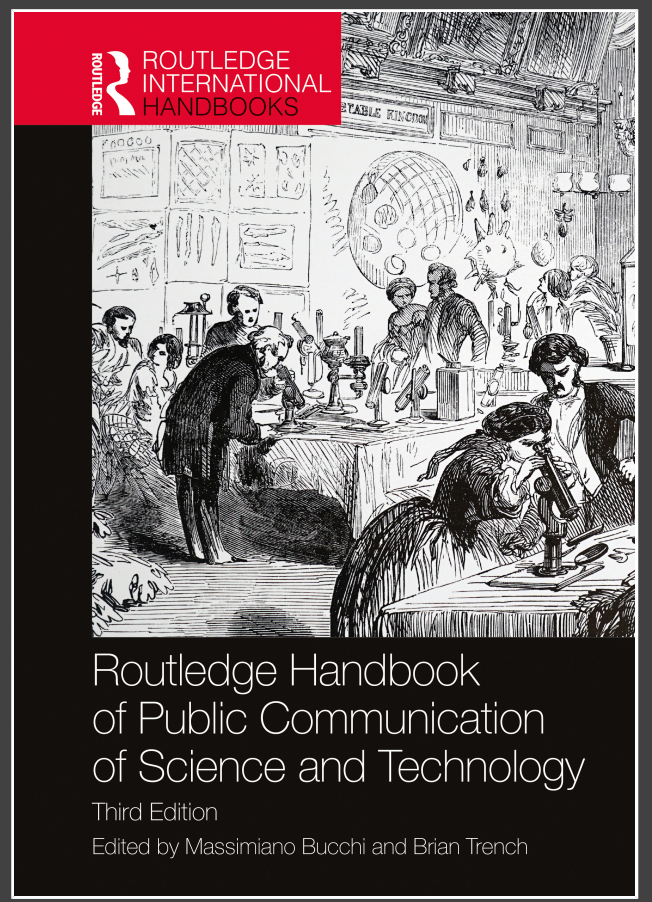

March 2021: 234x156: 344pp

8 illustrations

Hb: 978-0-367-48312-8 | £190.00

eBook: 978-1-003-03924-2

3RD EDITION

\title{
Routledge Handbook of Public Communication of Science and Technology
}

Edited by Massimiano Bucchi, University of Trento, Italy and Brian Trench, Dublin City University, Ireland

Series: Routledge International Handbooks

The third edition of the Handbook brings the reviews upto-date and deepens the analysis. As well as substantial reworking of many chapters, it includes four new chapters addressing enduring themes (science publics, science-media theories), recent trends (art-science interactions) and new proposed insights on science communication as culture and as "the social conversation around science".

Combining the perspectives of different disciplines and of different geographical and cultural contexts, this original text provides an interdisciplinary as well as global approach to public communication of science and technology.

\section{0\% Discount Available - enter the code FLY21 at checkout*}

Hb: 978-0-367-48312-8 | £152.00

* Offer cannot be used in conjunction with any other offer or discount and only applies to books purchased directly via our website.

To order an eBook for review, please complete the form at: https://m.email.taylorandfrancis.com/Review_copy_request 